\title{
Sürü Robotları için Esnek ve Ölçeklenebilir Toplanma Davranışı Metodu
}

\author{
Oğuz Misir ${ }^{1}$, Levent Gökrem² \\ ${ }^{1}$ GaziosmanpaşaÜniversitesi, Mühendislik ve Mimarlık Fakültesi, Mekatronik Mühendisliği Bölümü, Tokat, Türkiye (ORCID: 0000-0002-3785-1795) \\ ${ }^{2}$ GaziosmanpaşaÜniversitesi, Mühendislik ve Mimarlık Fakültesi, Mekatronik Mühendisliği Bölümü, Tokat, Türkiye (ORCID: 0000-0000-0000-0000)
}

(Bu yayın 26-27 Haziran 2020 tarihinde HORA-2020 kongresinde sözlü olarak sunulmuştur.)

(DOI: 10.31590 /ejosat.779162)

ATIF/REFERENCE: Mısır, O. \& Gökrem, L. (2020). Sürü Robotları için Esnek ve Ölçeklenebilir Toplanma Davranışı Metodu. Avrupa Bilim ve Teknoloji Dergisi, (Special Issue), 100-109.

\section{Öz}

Sürü robotiği, bir görevi üstün yeteneklere sahip birkaç robotun gerçekleştirmesinden farklı olarak, sınırlı ve basit yeteneklere sahip benzer robotlarla gerçekleştirmeyi amaçlayan bir yaklaşım olarak ortaya çıkmıştır. Bu yaklaşım doğada sürü halinde yaşayan karıncalar, termitler ve arılar gibi canlılardan ilham alınarak ortaya koyulmuştur. Sürü robotiğinde robotların aralarında koordinasyon kurabilmeleri için bir araya toplanmalıdırlar. Bu sebepten toplanma sürü robotiğinde uygulanan temel davranışlardan biridir. Bu çalışmada sürü robotları için toplanma davranışı metodu önerilmiştir. Önerilen toplanma metodu aynı özelliklere sahip sürü robotlarının, aralarında merkezi bir kontrolcü olmadan sadece sınırlı mesafe ve açı algılama sensör verileri ile bir araya toplanmaktadırlar. Önerilen toplanma metodu yaklaşma ve ortak yönde hareket kontrolcüsü ayrıca çarpışmadan ve engelden kaçınma kontrolcülerinden oluşmaktadır. Yaklaşma kontrolcüsü sürü robotlarını algılama alanı içerine giren robotlardan çoğunluğun olduğu yöne ilerlemelerini sağlamaktadır. Robotlar sınırlı algılama alanına sahip olduğundan sadece algıladıkları robotlarla toplanırlar. Böyle bir durumda robotlar kendi aralarında robot grupları oluştururlar. Oluşan robot gruplarının birleşebilmeleri için ortak yönde hareket kontrolcüsü kullanılmaktadır. Ortak yönde hareket kontrolcüsü gruplaşan robotları belirli bir yönde koordineli bir şekilde aynı yönde hareketini sağlar. Robot gruplarının ortak hareketi ile robotlar karşılaştıklarında birleşirler. Sürü robotlarının birbirlerine çarpacak kadar yaklaşmaları ve bir engelle karşılaşması durumunda engelden ve çarpışmadan kaçınmaları için ayrı bir kontrolör geliştirilmiştir. Her bir robot toplanma metodu ile sadece kendi kendine karar vererek bir araya gelmektedir. Bir merkezi kontrol birimine ihtiyaç yoktur. Robotların toplanma metodu ile hareketi öz örgütlenme (self organizing) organizasyonunu oluşturmaktadır. Çalışmada matlab benzetim ortamında sürü robotlarının toplanma davranışını sergiledikleri arena boyutunu ve robot sayısını değiştirerek önerilen toplanma metodu sistematik deneyler yoluyla incelenmiştir. Sistematik deneylerden elde edilen sonuçlara göre önerilen toplanma davranışının performansı değerlendirilmiştir.

Anahtar Kelimeler: Toplanma, Sürü Robotiği, Öz örgütleme, Koordineli Hareket, Flocking.

\section{Flexible and Scalable Aggregation Behavior Method for Swarm Robots}

\begin{abstract}
Swarm robotics has emerged as an approach that aims to perform a task with similar robots with limited and simple abilities, unlike a few robots with superior skills. This approach has been revealed by being inspired by living creatures such as ants, termites and bees living in flocks. In Swarm robotics, they must be gathered together so that robots can coordinate between them. For this reason, Aggregation is one of the basic behaviors applied in swarm robotics. In this study, aggregation behavior method is proposed for swarm robots. The proposed aggregation method combines only the limited distance and angle sensing capabilities of the swarm robots with the same characteristics, without a central controller between them. The proposed aggregation method consists of approach and a common directional motion controller, as well as collision and obstacle avoidance controllers. The approach controller allows the robots to move in the direction of the majority of the robots entering the detection area. Because robots have limited detection areas, they are
\end{abstract}

${ }^{1}$ Sorumlu Yazar: Tokat Gaziosmanpaşa Üniversitesi, Mühendislik ve Mimarlık Fakültesi, Mekatronik Mühendisliği Bölümü, Tokat, Türkiye, ORCID: 0000-0002-3785-1795, oguz.misir@gop.edu.tr 
aggregated only with robots they detect. In such a situation, robots form robot groups among themselves. A motion controller is used in a common direction for the robot groups that are formed to join. The motion controller in the common direction allows the grouped robots to move in the same direction, coordinated in a certain direction. With the joint movement of robot groups, robots unite when they meet. A separate controller has been developed for swarm robots to come close enough to hit each other and avoid obstacles and collisions if they encounter an obstacle. Each robot combines with the self organizing aggregation method only by deciding on its own. There is no need for a decentralized control unit. The movement of the robots with the method of aggregation constitutes the self organization organization. In the study, the proposed aggregation method was performed by systematic experiments by changing the arena size and the number of robots where the swarm robots exhibit their behavior in matlab simulation environment. According to the results obtained from systematic experiments, the performance of the proposed aggregation behavior was evaluated.

Keywords: Aggregation, Swarm robotic, Self-organization, Coordinated movement, Flocking.

\section{Giriş}

Sürü robotiği, sosyal böcekler, kuşlar, arılar gibi canlıların kendi kendine organizasyonundan(self-organizing) ilham alan bir araştırma alanıdır(Brambilla, Ferrante, Birattari, \& Dorigo, 2013; Nedjah \& Junior, 2019; Yılmaz \& Bayındır, 2019). Sürü robotları, canlılardan ilham aldıkları davranışlarda gözlemlendiği gibi kendi kendine karar vererek hareket etmeleri amaçlanmaktadır(Bayındır, 2016; S Camazine vd., 2003). Sürü robotları, icra edecekleri görevler için çevresiyle ve kendi aralarında etkileşim kurarlar. Robotlar, kendi aralarında ve robot-çevre etkileşimi için algılama gereksinimleri karşılayabilecek basit özelliklerde olmalıdırlar. Ayrıca her bir sürü robotunun kendi kendini organize olabilmesini sağlayacak kontrolcüye sahip olmalıdır.(Abuelhaija, Jebrein, \& Baldawi, 2020).

Sürü robotiğindeki, robotların yürüteceği görevler ve sergileyecekleri davranışlar için sahip olması gereken özellikler aşağıdaki gibi siralanmaktadır(O. Soysal \& Sahin, 2005).

- Robotlar çevreyi etkili bir biçimde algılamalı ve özerk olmalı,

- Bir görevi icra eden üyeler homojen olmalı kısaca hepsi aynı yetenekte olmalı,

- Robotlar karşılaştıkları problemler karşısında sadece bir robotun bu problemi çözemeyecek yetenekte olmalıdır.

Sürü robotiğinde, robotların olabildiğince basit donanım özelliklerine ve tasarıma sahip olması beklenmektedir(Shlyakhov, Vatamaniuk, \& Ronzhin, 2017). Aynı zamanda sürü robotlarının iş birliği içerisinde hareket edebilecek yetenekte olmalıdırlar. Doğada karşılaşılan sosyal canlıların(arılar, hamamböcekleri vb.) icra ettikleri görevlerde esnek, ölçeklenebilir ve sağlam oldukları gözlemlenmiştir(Scott. Camazine vd., 2001). Sürü robotiğinde, canlıların bu davranışları ilham kaynağı olmuştur.

Sürü robotiği ile ilgili yapılan çalışmalarda çoklu robot uygulamaları sürü robotiği davranışı olarak isimlendirilmektedir. Bu davranışlar toplanma, koordineli hareket, model oluşturma, kendi kendini iyileştirme(self-deployment), kendi kendine montaj(self assembly) olarak sıralanmaktadır(Dudek, Jenkin, Milios, \& Wilkes, 1996; Şahin \& Bayındır, 2014). Sürü robotiğinde birçok davranış sergilenmeden önce aralarında organize olabilmeleri için bir araya gelmelidirler. Bu sebepten toplanma davranışı(aggregation) sürü robotlarının bir araya gelmesinde ön koşul olarak temel bir öneme sahiptir.

Toplanma(aggregation) davranışı doğada karşılaşılan temel davranışlardan biridir(Trianni, Groß, Labella, Şahin, \& Dorigo, 2010). Bu davranış böcekler, bakteriler, memeliler ve tek hücreli canlıların, hayatta kalmalarına ve kendilerini korumalarına yardımcı olmaktadır(O. Soysal \& Sahin, 2005). Toplanma davranışı canlıların belirli bir bölgede bir araya toplanması olarak gözlemlenmektedir(Martínez-Clark, Cruz-Hernández, Pliego-Jimenez, \& Arellano-Delgado, 2018). Canlılarda toplanma davranışı işarete tabanlı(cue-based) ve öz örgütlenebilir(self-organizing) olarak ikiye ayrılmaktadır(Hu, Zhong, Zhang, \& Yao, 2014). İşaret yoluyla toplanma(aggregation) 1sı, 1şık, ferromon gibi aracıların yardımıyla gerçekleşmektedir. Öz örgütlenebilir toplanma davranışı yardımcı bir aracı kullanmamaktadır.

Sürü robotiğinde de toplanma davranışı işaret tabanlı ve öz-örgütlenebilir olarak incelenmektedir(Arvin vd., 2014; Khaldi, Harrou, Cherif, \& Sun, 2019). Sürü robotiğinde toplanma davranışının literatürde yapay fizik algoritmaları(virtual forces)(Khaldi, Harrou, Cherif, \& Sun, 2018a; Vanualailai \& Sharma, 2010), olasılıksal yöntemler(probablistic methods)(Arvin, Samsudin, Ramli, \& Bekravi, 2011; Hamann, Worn, Crailsheim, \& Schmickl, 2008; Kernbach vd., 2013) ve evrimsel metotlar(evolutionry methods) olarak incelenmektedir(de Sá, Nedjah, \& Mourelle, 2017; Francesca, Brambilla, Trianni, Dorigo, \& Birattari, 2012; Gauci, Chen, Li, Dodd, \& Groß, 2014a; Gomes, Urbano, \& Christensen, 2013; Khaldi vd., 2018a).

Yapay fizik algoritmaları robotların kendi aralarında ve çevresiyle olan etkileşimlerde yaklaşma, durma, çarpışmadan kaçınma gibi fiziki hareketleri yapay olarak algoritmalarla modellenmesidir(Bayındır, 2016). Araştırmacılar Lyapunov yaklaşımı ile robotların aralarındaki uzaklıklara göre birbirlerine yaklaştıklarında uzaklaşma, uzaklaştıklarında yaklaşma gibi fiziksel kuralları yapay olarak modellemişlerdir. Bu çalışmada robotlar aralarında çarpışmadan hareket etmektedir(Vanualailai \& Sharma, 2010). Başka bir çalışmada robotlar arasındaki mesafenin yanı sıra robot yoğunluğunun da önemli olduğu vurgulanmıştır. Araştırmacılar DW-KNN(DistanceWeighted K-Nearest Neighbouring) topolojisini kullanılarak çok sayıda robotu bir araya getirmişlerdir(Khaldi, Harrou, Cherif, \& Sun, 2018b). Olasılıksal yöntemler (probablistic methods) ile ilgili yapılan çalışmalarda genellikle robotların bir araya gelebilmeleri için kendi aralarında bekleme, durma, itme, çekme, ilerleme gibi durumlar için robotlar modellenmektedir. Araştırmacılar robotların bu durumları için olasılıksal sonlu durum makinesi yöntemini kullanarak toplanma davranışını robotlara uygulamışlardır(Amé, Halloy, Rivault, Detrain, \& Deneubourg, 2006; Hu vd., 2014; O. Soysal \& Sahin, 2005; Onur Soysal, Bahçeci, \& Şahin Erol, 2007; Yan, Liang, 
\& Guan, 2011). Evrimsel metotlar ile ilgili yapılan çalışmalarda ise robotların sahip olduğu algılayıcılardan alınan girdilerle robotlara evrimsel kontrolcülerle toplanma davranışını uygulayan çalışmaları içermektedir(de Sá vd., 2017; Gauci, Chen, Dodd, \& Groß, 2014a; Sathiya \& Chinnadurai, 2019). Evrimsel kontrolcüler, genetik algoritma (genetic algorithm), takviyeli ögrenme(reinforcement learning), q- Truva, novelty research ve yapay sinir ağları gibi yöntemleri içermektedir(Gauci, Chen, Dodd, vd., 2014a; Gomes vd., 2013; Nakano, Bandala, Faelden, Maningo, \& Dadios, 2014; Shao, Lin, \& Zhang, 2013).

$\mathrm{Bu}$ çalışmada sürü robotiğinde toplanma davranışı için kendi kendilerine örgütlenebilen (öz örgütlenme- self-organizing) toplanma davranışı yöntemi önerilmiştir. Sürü robotları merkezi bir kontrolcü kullanmadan aralarında iş birliği kurarak toplanma davranışı sergileyebilmeleri amaçlanmaktadır. Önerilen çalışmada sürü robotları algıladıkları komşu robotların açı ve uzaklık bilgilerini kullanarak toplanma davranışını sergilemektedirler. Robotlar algıladıkları komşu robotlarla etkileşim kurabilmeleri için uzaklık ve açı bilgilerini algılayabilmektirler. Ayrıca sürü robotları algıladıkları komşu robotların baş açılarını ölçebilmeleri için aralarında baş açılarını paylaşmaktadırlar.

Sürü robotları algıladıkları komşu robotların açı ve uzaklıklarına bağlı olarak hangi yönde ve hızda hareket edeceğine karar verebilmektedirler. Önerilen toplanma davranışı yöntemi 2 aşamadan ve çarpışmadan ve engelden kaçınma metotlarından oluşmaktadır. İki aşamalı kontrolcü yaklaşma ve ortak yönde hareketi içermektedir. Yaklaşma aşamasında, robotlar algıladığı komşu robotların açılarının ortalamasına göre bir yönelme açısı belirler. Böylece en fazla sayıdaki robotun bulunduğu yöne doğru hareket eder. Ortak yönde hareket aşaması, birbirlerine çarpamayacak kadar yaklaşan robotların en yakınındaki robotu takip etmesini sağlamaktadır. Sürüde bulunan robotların birbirlerine yaklaşması durumunda farklı sayıda robot grubunun oluşmasına yol açar. Farklı sayıda oluşan robot gruplarının birleşmesi için grupların ortak yönde hareketi ile sağlamaktadır. Robotların bir engelle veya aralarında birbirine çarpışacak kadar yaklaşması durumları için çarpışma ve engelden kaçınma metodu önerilmiştir. Toplanma davranışının amacı ise sürüde bulunan bütün robotların birbirlerini algılayabilecek kadar bir araya toplanmalıdır.

Önerdiğimiz yaklaşımın ana katkısı, sürü robotlarının kısıtlı algılama parametrelerini kullanarak toplanma davranışını sergilemesidir. Sürü robotları herhangi bir merkezi kontrolcü kullanmadan sadece komşu robotları algılama açısı, uzaklığı ve baş açısına göre toplanma davranışını sergilemektedir. Çalışmada önerdiğimiz toplanma davranışının ölçeklenebilirliğini ve esnekliğini değerlendirmek için farklı robot sayısı ve arena boyutu göre sistematik deneyler gerçekleştirilmiş̧tir. Sistematik deneyler yoluyla elde edilen sonuçlara göre önerilen toplanma davranışı yöntemi değişen robot sayısı ve arena boyutu göre ölçeklenebilir ve esnek davranış sergilemiştir.

Makalenin geri kalanında takip edildiği gibi organize edilmiştir. Bölüm 2 'de problem tanımı ve simülasyon ortamında kullanılan sürü robotunun özellikleri verilmektedir. 3. bölüm benzetim ortamında uygulanan sistematik deneylerin kurulumunu ve deney sonuçlarını içermektedir. Son olarak, 4. bölüm sonuç 'tan oluşmaktadır.

\section{Metot}

\subsection{Sürü Robotu Modeli ve Özellikleri}

Şekil 1. 'de gösterildiği gibi sürü robotu dairesel yapıya sahiptir. Sürü robotu holonomik olmayan bir yapıdadır. Her robot 0,15 birimlik robot çapından oluşmaktadır. Sürü robotu 6 birim yarıçapında $\theta=360^{\circ}$ derece algılama açısıyla etrafındaki bütün robotları algılayabilmektedir. Sürü robotları algıladığı robota olan uzaklığını $\left(\mathrm{R}_{r, n}\right)$, açısı $\left(\theta_{r, n}\right)$, algıladığı robotun hangi baş açısını $\left(\emptyset_{r, n}\right)$ ve algılama sınırları içerisindeki robot sayısını $(\mathrm{n})$ hesaplayabilmektedir. $\left(\mathrm{R}_{r, n}\right),\left(\theta_{r, n}\right)$ ve $\left(\emptyset_{r, n}\right)$ için $\mathrm{r}$ burada algılayan robotun numarası iken $\mathrm{n}$ ise algılanan robotun numarasıdır. Sürü robotu 45 'er derece açılarlara yerleştirlimiş 8 adet engel algılama sensoru ile donatılmıştır. Engel algılama sensorleri 1 birime kadar olan engellerin uzaklığını ve açılarını $\left(O_{\alpha}\right)$ 'ini ölçebilmektedir. Burada $\alpha=[-$

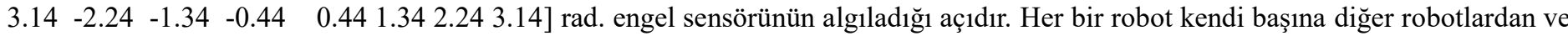
merkezi bir kontrolcüden bilgi almadan özerk olarak hareket etmektedir. Sürü robotiği yaklaşımı gereği her bir robot aynı özelliklere sahiptir.

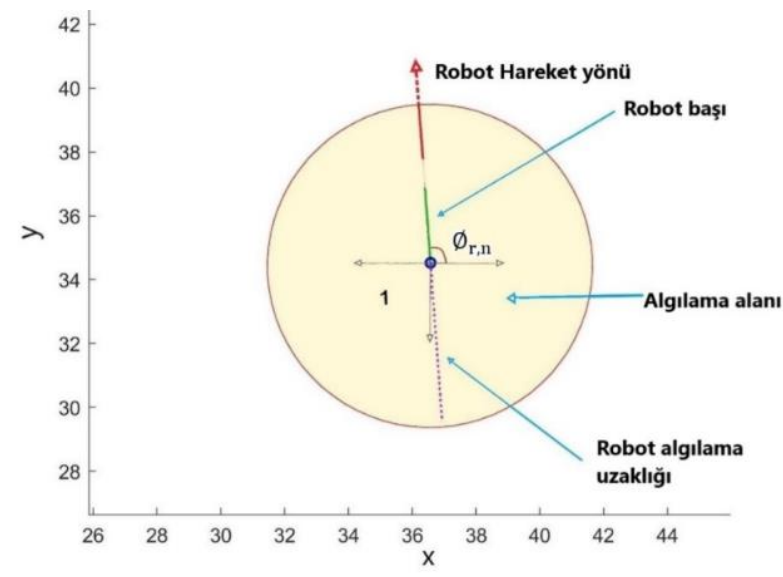

Şekil 1. Sürü Robotu ve Özellikleri 
Şekil 2. 'de sürü robotunun bir robotu algılama senaryosu gösterilmektedir. Senaryoda 15 ve 7 numaralı sürü robotları birbirlerinin algılamaktadır. 15 numaralı robot, 7 numaralı robotu $\left(\mathrm{R}_{15,7}\right)$ uzaklığında 7 numaralı robot 15 numaralı robotu $\left(\mathrm{R}_{7,15}\right)$ uzaklığında olduğunu ölçebilmektedir. Aynı şekilde 15 numaralı robot 7 numaralı robotu $\left(\theta_{15,7}\right)$ açısıyla 7 numaralı robot 15 numaralı robotu $\left(\theta_{7,15}\right)$ açısında olduğunu ölçebilmektedir. Senaryoda birbirlerinin algılama sınırı içerisinde olan sürü robotları birbirlerinin baş açılarını IR gibi haberleşme yöntemi ile paylaşabilmektedir. 15 numaralı robot 7 numaralı robotun baş açısını $\left(\emptyset_{15,7}\right)$ olarak algılamaktadır. Aynı şekilde 7 numaralı robot 15 numaralı robotun baş açısını $\left(\emptyset_{7,15}\right)$ olarak algılamaktadır.

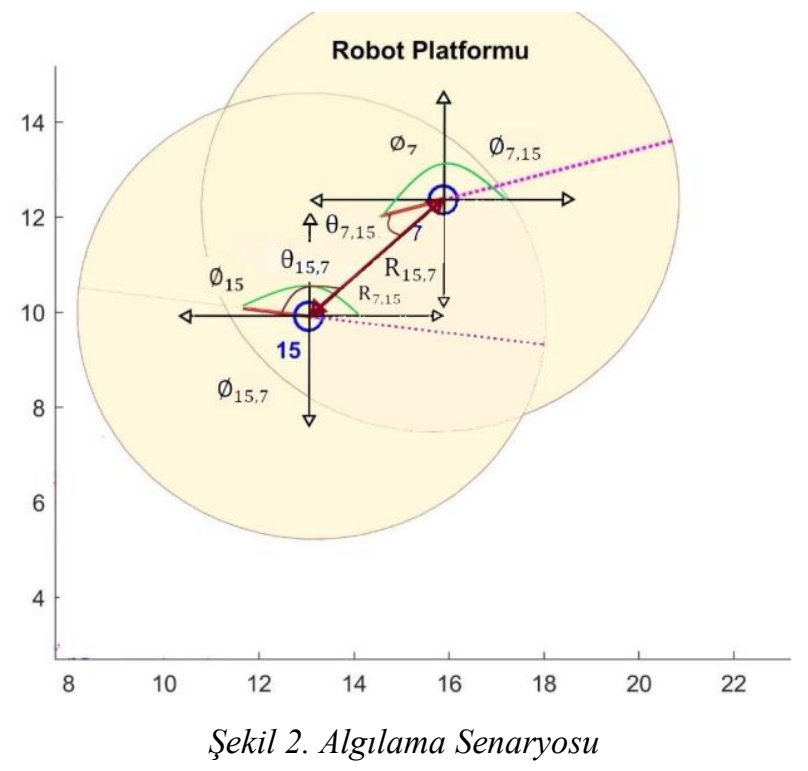

\subsection{Problem Tanımı}

Benzer özelliklere sahip robotlar küresel referans çerçevesi üzerindeki hareketi denklem (1) 'de ifade edilmektedir. Denklem (1) ‘e

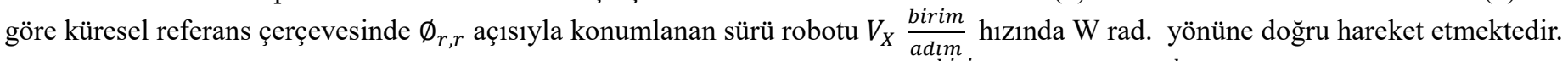
Burada $\emptyset_{r, r}$ sürü robotunun kendi baş açısıdır. $X_{\mathrm{n}}$ ve $\mathrm{Y}_{\mathrm{n}}$ sürü robotunun $V_{X} \frac{\text { birim }}{\text { adım }}$ hızında $\mathrm{W} \frac{\mathrm{rad}}{\text { adım }}$ açısal hızındaki elde edilen konumunu ifade etmektedir. $X_{n}$ ve $Y_{n}$ pozisyonları sürü robotunun son konumunun üstüne eklenmektedir. Böylece sürü robotunun son konumu bulunur.

$$
\left[\begin{array}{c}
X_{n} \\
Y_{n} \\
w
\end{array}\right]=\left[\begin{array}{cc}
\cos \left(\emptyset_{r, r}\right) & 0 \\
\sin \left(\emptyset_{r, r}\right) & 0 \\
0 & 1
\end{array}\right]\left[\begin{array}{c}
V_{X} \\
W
\end{array}\right]
$$

Küresel referans çerçevesi sürü robotlarının hareket ettikleri arenadır. Arenanın etrafı engeller ile sınırlandırılmıştır ve kare şeklindedir. Şekil 3. 'de 10 adet sürü robotunun etrafi engellerle çevrili küresel referans çevresindeki yerleşimi örnek olarak gösterilmektedir. Her bir sürü robotu 1'den 10’a kadar numaralandırılmıştır. Sürü robotların her biri aynı özelliklere sahiptir.

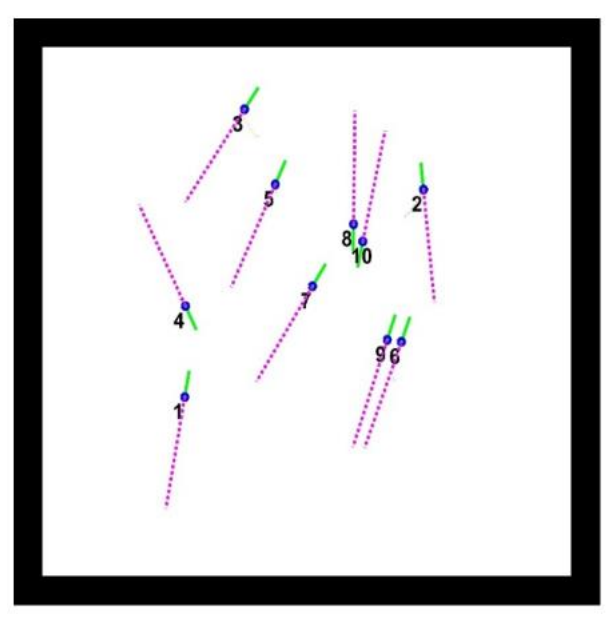

Şekil 3. Küresel referans çerçevesine konumlanan sürü robotları 
Toplanma(aggergation) sürü robotlarının tek bir aggrega(küme-topluluk) oluşturacak şekilde bir araya gelmesidir(Gauci, Chen, Li, Dodd, \& Groß, 2014b). Bu çalışmada aynı özelliklere sahip sürü robotlarının bir araya toplanması amaçlanmaktadır. Engellerle sınırlandırılmış arenada birçok sayıda sürü robotunun birbirlerine ve engele çarpmadan bir araya gelmeleri için çözüm üretilmektedir. Sürü robotları araneya aggregation davranışına başlamadan önce rasgele konumlandırılmaktadırlar. Toplanma davranışı sergilenirken sürü robotları çevresinden ve robotlar arasında herhangi bir yardımcı işaret kullanmadan bir araya toplanmaları amaçlanmaktadır.

\subsection{Aggregation Metodu}

Sürü robotlarının herhangi bir merkezi kontrolcü kullanmadan bir araya gelmeleri yaklaşma, ortak yönde hareket ve çarpışma/engelden kaçınma durumlarını içeren bir aggregation yöntemi önerilmiştir. Kontrolcünün 1. aşaması yaklaşma ve 2. aşaması ortak yönde harekettir. Şekil 4. 'de önerilen aggregation metodunun akış diyagramı gösterilmektedir. Akış diyagramı sürü robotlarının bireysel hareketini içermektedir. Bireysel hareket eden sürü robotları organize bir şekilde kendi kendilerine toplu davranış sergileyebilmektedirler. Sürü robotu bireysel olarak bir robot algılaması durumunda yaklaşma ve ortak yönde hareket aşamalarından uygun olanı seçer. Böylece sürü robotları öz-örgütlenebilir bir şekilde toplama davranışını uygulamaktadır. Sürü robotu bir engel veya bir robota çarpışacak kadar yaklaşır ise engelden kaçınma metodunu uygulamaktadır. Eğer sürü robotu bulunduğu arenada bir robot veya engel ile karşılaşmaması durumunda robot veya engel bulana kadar rasgele hareket etmektedir.

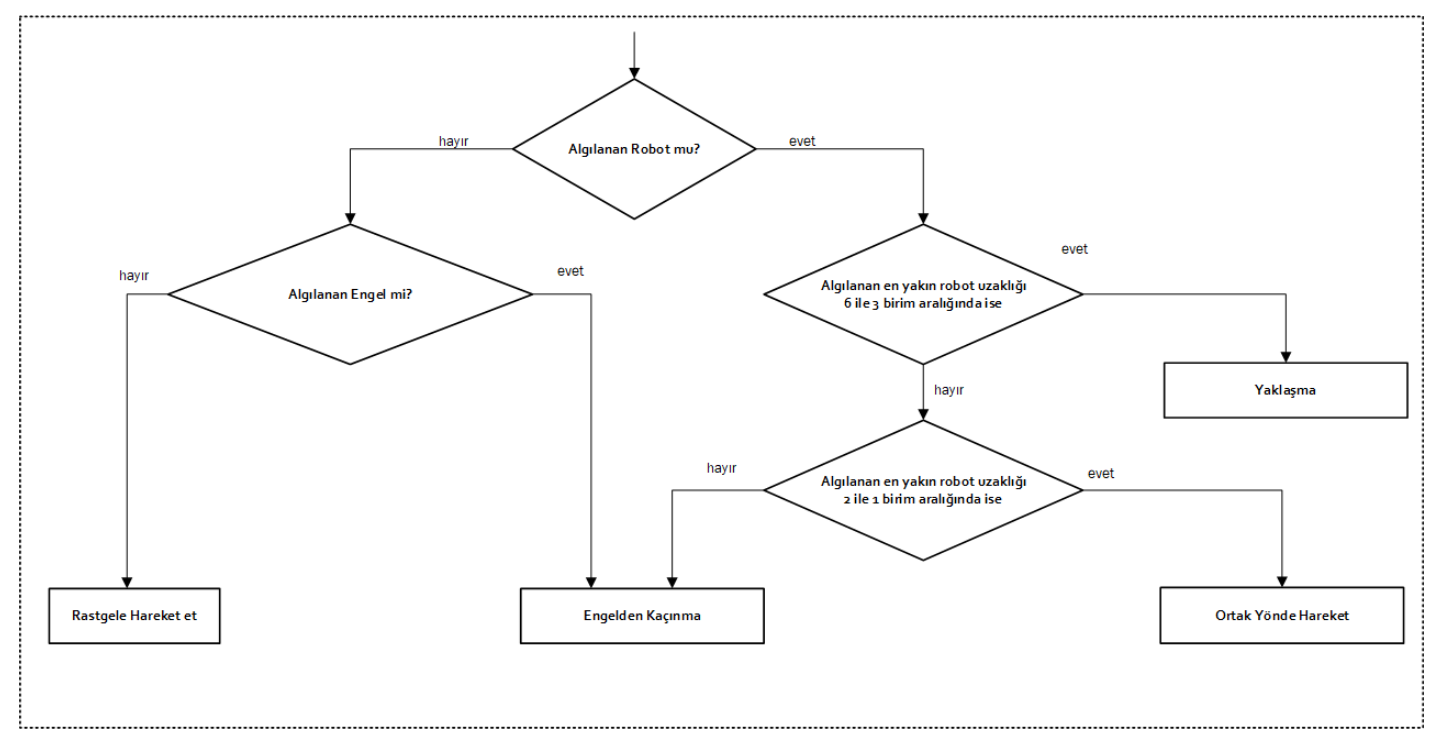

Şekil 4. Aggregation Metodu akış diyagramı

\subsubsection{Yaklaşma}

Sürü robotu herhangi bir robot ile karşılaşması durumunda ve algıladığı robotlardan en yakınıyla arasında 3 ile 6 birim uzaklık varsa yaklaşma aşamasını uygulamaktadır. Yaklaşma aşamasında sürü robotu denklem (2) 'de ifa edildiği gibi komşu robotları algıladığı açıların ortalamasını hesaplar.

$$
\beta_{r}=\frac{1}{n} \sum_{1}^{n} \mathbf{R}_{\mathrm{M}_{\mathrm{n}}}
$$

Sürü robotu komşu robotları algıladığı açıların ortalaması $\boldsymbol{\beta}_{\boldsymbol{r}}$ ile ifade edilmektedir. Burada $\mathrm{r}$ algılayan robotun $\mathrm{n}$ ise algılanan robotun numarasıdır. Yaklaşma aşamasında algılayan sürü robotunun belirlediği dönüş yönü $\boldsymbol{\beta}_{\boldsymbol{r}}$ denklem (1) 'de ifade edilen $\mathbf{W}$ açısal hızına

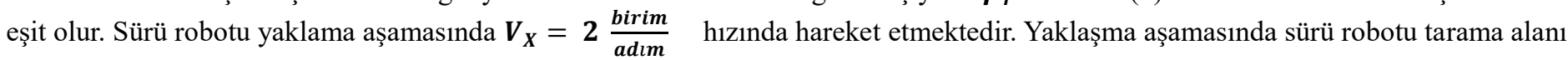
içerisindeki robot yoğunun en fazla olduğu yöne ilerlemesini sağlanmaktadır. Dolayısıyla robot, çoğunluğun bulunduğu yönü tercih etmiş olur. Robotun bu ilerleyişi algıladığı robotlara olan uzaklığı azaltır.

\subsubsection{Ortak Yönde Hareket}

Sürü robotu algıladığı en yakın robot ile arasında 1 ile 3 birim mesafe var ise ortak yönde hareket metodunu kullanmaktadır. Ortak yönde hareket en yakın komşu robotun hareketine bağlı olarak belirlenir. Denklem (3)' de ifade edildiği gibi algıladığı komşu robotlardan en yakın olanın baş açısını seçimi yapılır. Sürü robotu ortak yönde hareket ile önerilen metotta 1. aşamada birbirlerine yaklaşan robotlar aralarında birden fazla robot grubu oluşuna sebep olur. Ortak yönde hareket ile birbirlerinin en yakınındaki robotu takip eden robotlar organize bir şekilde birleşemediği diğer robot gruplarını arar. 
$\emptyset_{e n k_{r}}=\min \left(R_{r, n}\right) \rightarrow \emptyset_{r, n}$

Ortak yönde hareket sürü robotlarının en yakınındaki robot ile kordinasyonunu sağlar. Bütün robotlar birbirlerine yaklaşsa dahi bir ortak yönde hareket yapabilirler. En yakınındaki robot takibi birbirlerini algılayan robotların zincirleme birşekilde aynı yönde gitmesini sağlamaktadır.

\subsection{1 Çarpışmadan ve Engelden Kaçınma}

Sürü robotları bir engel ile karşılaşması durumunda veya birbirlerine çarpacak kadar yakın olmaları durumunda çarpışma ve engelden kaçınma metodu kullanılmaktadır. Sürü robotu bir 1 birim uzaklı̆̆a kadar bir engelle veya robot ile karşılaşırsa denklem (4) 'de ifade edildiği gibi hareket etmektedir. Denklem (4)' de sürü robotunun engel algılama sensorlarının algıladığı açıların ortalaması sıfırdan küçük eşit ise ya da engel robotu sağ tarafında ise robotun dönüş yönü sol olarak $(\pi)$ olarak belirlenir. Engel algılama sensorlerinin algıladığı açıların orlaması sıfırdan büyük ise robotun dönüş yönü sağ olarak $(-\pi)$ belirlenir. Çarpışmadan ve engelden kaçınma durumunda robot hızı $\boldsymbol{V}_{X}=\mathbf{1} \frac{\text { birim }}{\text { adlm }}$ 'dir.

$$
\left\{\begin{aligned}
W=\pi & \sum o_{\alpha} \leq 0 \\
W=-\pi & \sum o_{\alpha}>0
\end{aligned}\right.
$$

Sürüdeki her bir robot sadece algıladıkları robotların açı ve uzaklık bilgileri ile toplanırlar. Algılama alanı içerisindeki bütün robotlar birbirlerini zincirleme olarak takip ederler. Bazı robotlar birbirlerini algılamasa da birlikte hareket ederek bir grupta toplu olarak kalırlar. Robotlar kendi kendine organize olurlar (öz örgütlenirler). Merkezi bir kontrolcü olmadan robotlar sadece algıladıkları robotların yön ve uzaklıklarına bağlı olarak toplanırlar.

\section{Deneysel kurulum ve Deney sonuçları}

Önerilen öz-örgütlenebilir aggregation metodunu ölçeklenebilirlik ve esneklik bakımından sistematik deneyler yoluyla incelenmektedir. Sistematik deneyler, sürü robotlarını farklı büyüklükteki engellerle sınırlandıılmış arenalarda ve farklı sayıda aynı özelliklere sahip robotlarla uygulanmaktadır. Önerilen öz-örgütlenebilir aggregation metodu için uygulanan deneyler Matlab benzetim ortamında uygulanmıştır.

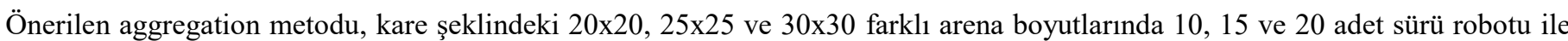
sistematik deneyler uygulanmıştır. Her bir arena boyutu ve robot sayısı için kombinasyonlu sistematik deneyler uygulanmıştır. Her bir kombinasyon için deneyler 10 kez tekrarlanmıştır.

\section{1 Ölçümler}

Önerilen aggregation metodunun farklı arena boyutlarında ve farklı sayıda uygulanan sistematik deneylerde toplanma davranışı performansı ile değerlendirile bilmektedir. Toplanma davranışı performansı için sürü robotlarının herhangi sürü robotundan biri diğer sürü robotlarını algılaması durumunda benzetim ortamında uygulanan iterasyon sayısı referans alınmaktadır.

\subsection{Deney sonuçları}

Önerilen toplanma metodunun performansı farklı arena boyutlarında ve farklı robot sayılarında uygulanan sistematik deneylerle değerlendirilmiştir. Şekil 5. 'de 20×20, $25 \times 25$ ve $30 \times 30$ arena boyutlarında 10,15 ve 20 robot ile uygulanan sistematik deney sonuçları kutu diyagramı olarak gösterilmektedir. Kutu diyagramlarının her biri arena boyutu ve robot sayısı için uygulanan deneyi ifade etmektedir. Kutu diyagramları uygulanan deneyin iterasyon(adımlar) sayısına bağlı olarak, alt değer uygulanan deneyin en az iterasyon sayısını üst değeri veya kırmızı "artı(+)" işareti en fazla iterasyon sayısına karşılık gelmektedir. Ek olarak kutu diyagramlarında gösterilen kırmızı düz çizgi ise uygulanan deneylerin ortanca(medyan) değerini ifade etmektedir. Deney sonuçlarından elde edilen medyan değeri ise uygulanan deneyin performansıdır. 


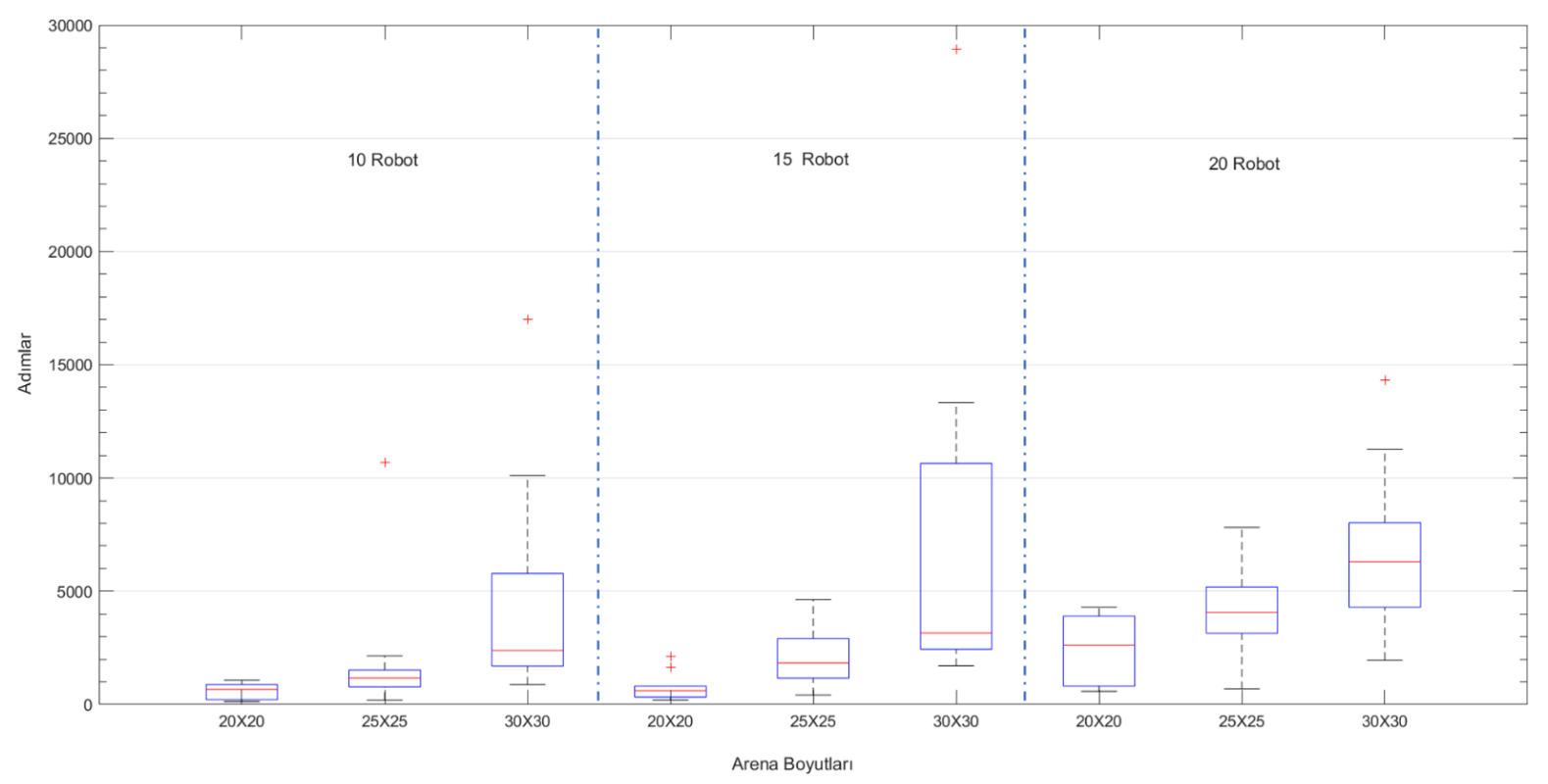

Şekil 5. Aggregation Metodu akış diyagramı

Uygulanan sistematik deneylerden elde edilen sonuçlara göre ölçeklenebilirlik açısından değerlendirildiğinde sürü robotlarının sayısı artıkça toplanma davranışııın performansı iterasyon sayısı bakımından azalmaktadır. Ölçeklenebilirlik açısından performansı değerlendirildiğinde arena boyutu büyüdükçe toplanma davranışının performansı azalmıştır. Herhangi bir sürü robotunun diğer robotların tümünü algılaması durumuna deneyler sonlandırıldığından uygulanan tüm deneylerde toplanma davranışı gerçekleşmiştir.

Arena boyunun artmasına bağlı olarak toplanma davranışının performansının azalmasııın temel sebebi, uygulanan deneylerin başlangıcında sürü robotları arena boyutuna göre dağıtılmasıdır. Arena boyutuna göre rastgele dağıtılan sürü robotları arasındaki uzaklıkta artmaktadır. Arena boyutuna göre birbirinden farklı konumlara rastgele dağıtılan sürü robotlarından birbirlerine yakın olanlar bir araya gelip bir robot grubu oluşturmaktadır. Birden çok robot grubunun birleşmesi iste simülasyon iterasyon sayısında artışa sebep olur.

Robot sayısının artmasına bağlı olarak toplanma davranışının azalmasının ana sebebi ise robot sayısının artmasıyla robotlar arasındaki koordinasyon, iterasyon sayısının artmasına sebep olmaktadır. Sürü robotu algıladığı diğer robotların açı ve uzaklık bilgilerine göre hareket ettiğinden algıladığı her bir robotun bu parametrelerini de algılamaktadır. Böylece bir sürü robotunun algıladığı sürü robotu sayısı artıkça işlem yüküde artar.

Şekil 6. ‘de 20x20 arena boyutlarında 20 aynı özelliklere sahip sürü robotunun toplanma davranışı için başlangıç ve tamamlanması gösterilmektedir. 20x20 boyundaki arenada uygulanan deney başlangıcında birbirinden farklı konumlara rastgele dağıtılan sürü robotlarından bazıları birbirlerini algılasa da toplanma şartını gerçekleştirmemektedirler. Önerilen toplanma davranışı metoduna göre hareket eden sürü robotları 4264. iterasyonda toplanma davranışını gerçekleşmişlerdir.
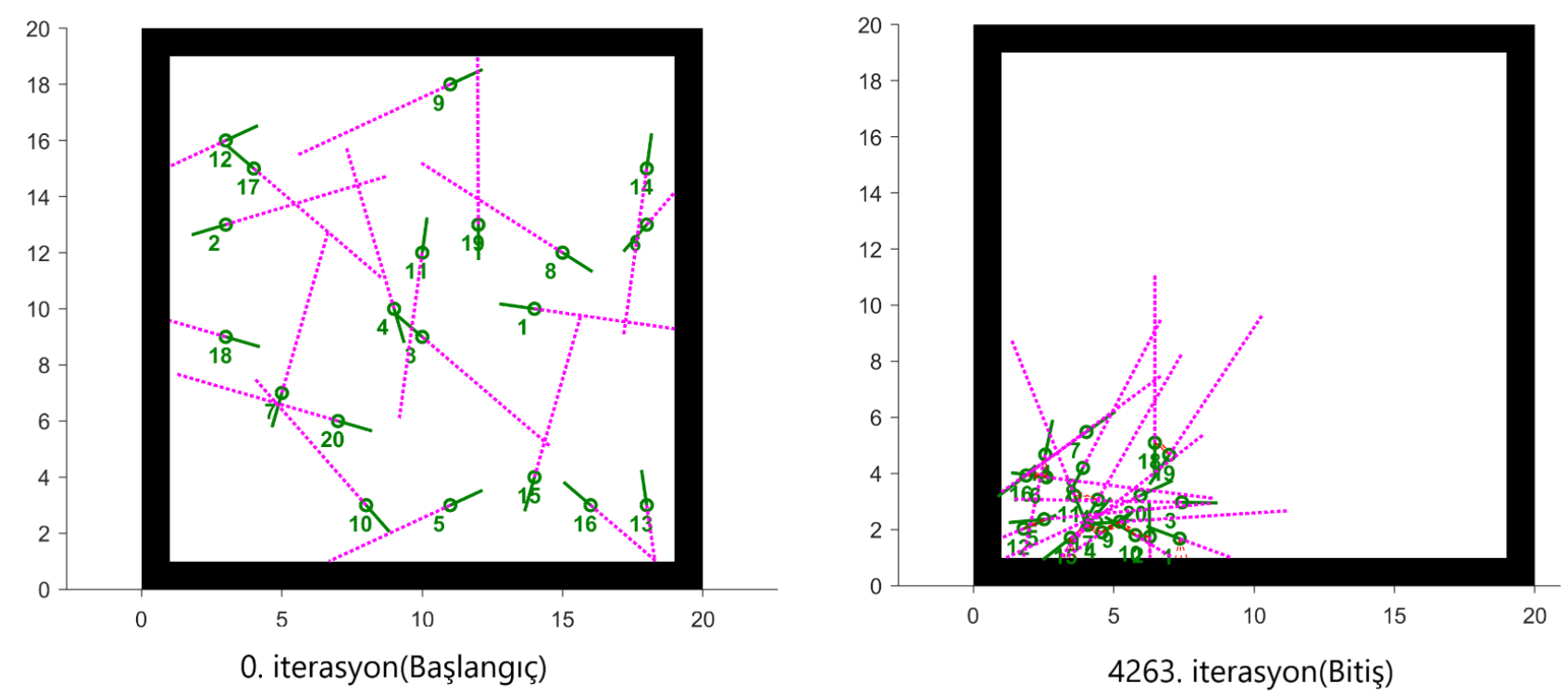

Şekil 6. 202x20 arena boyutunda 20 sürü robotunun toplanma davranışı 
Şekil 7. ‘da $20 \times 20$ arena boyutlarında 20 aynı özelliklere sahip sürü robotunun toplanma davranışı metodunu uygulayan sürü robotlarının aralarındaki toplam uzaklık gösterilmektedir. Toplanma davranışı boyunca sürü robotları arasındaki uzaklık gidere azalmaktadır. Toplanma davranışı robotu yaklaşma durumunda robotları bir araya getirmektedir. Ortak yönde hareket durumunda ise sürü robotları en yakanındaki sürü robotunu takip etmektedir. Şekil 6. 'da ilk 700 iterasyon boyunca sürü robotları arasındaki uzaklık kayda değer bir şekilde azalmıştır. Bunun temel sebebi birbirlerine yakın olan sürü robotlarının yaklaşma koşulunu yerine getirmeleridir. 700. iterasyondan sonra robotlar arasındaki uzaklık iterasyon arttıkça dalgalanma (artış veya azalış) göstermektedir. Bu dalgalanma sürecinde sürü robotları aralarında ortak yönde hareket veya engelden kaçınma durumlarını yerine getirmektedirler.

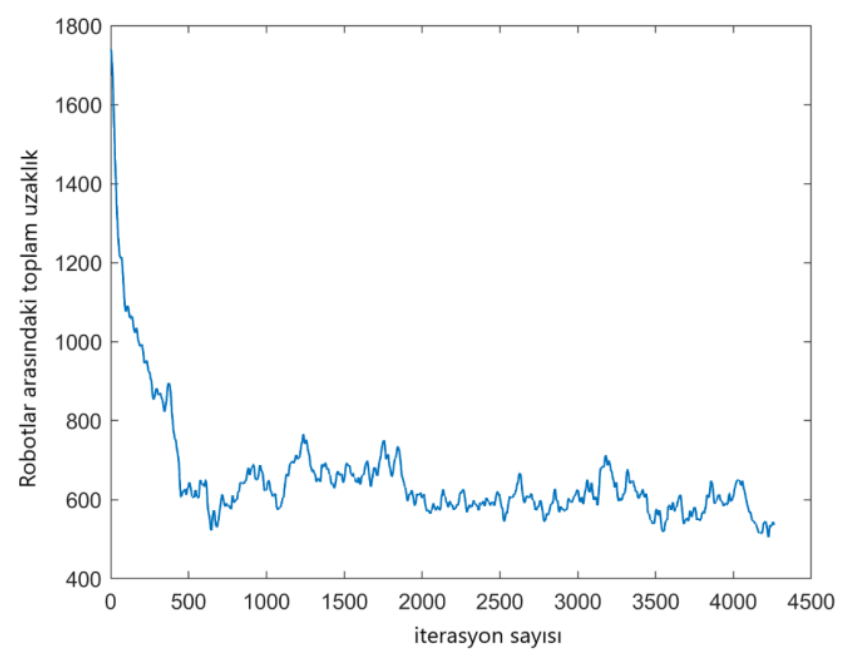

Şekil 7. $202 \times 20$ arena boyutunda 20 sürü robotunun toplanma davranışl süresince aralarındaki toplam uzakllk

Robotlar öz örgütlenebilir toplanma metodunu uygulandığında;

- Herhangi bir robot algılama alanına girdiğinde en çok robotun olduğu yöne yaklaşır,

- Sürü robotu hiçbir robot algıllayamaz ise $2 \frac{\text { birim }}{\text { adım }}$ sabit hızda rastgele robot arar,

- Sürü robotları, birbirlerine toplanma metodundaki ortak yönde hareket sergileyecek kadar yaklaşırlarsa algıladıkları robotlarla aralarında iş birliği yaparlar ve aynı yönde hareket ederler.

- Robotlar sadece algıladıkları sınır içerisindeki robotlara göre hareket ederler, algılanamayan diğer robotlar da kendi aralarında birleşir ve robot grupları oluşturur. Böyle bir durumda birbirlerine yaklaşan robotlar aynı yöne yönelir. Robotların tamamı birbirini görmese de grup halindeki robotlar birleşmek için aynı yönlerde hareket ederler. Bu sayede birbirini algılamayan robot grupları karşılaşıtıklarında birleşirler.

Robotlar birbirlerini algılamamalarına rağmen ortak algıladıkları ortak robotlar bulunur. Ortak algıladıkları robotlar sayesinde birbirini görmeyen robotlar bir takip zinciri oluşturur. Bu takip yapısı ile robotlar birbirlerine bağlı kalır. Toplanma metodu ile her robot sadece kendi başına karar verir bu da öz örgütlenme yapısını oluşturur. Robotların aralarındaki bu ilişki sayesinde toplandıkları robotlarla koordinasyon kurmalarını sağlar. Sürüde bulunan robotlardan biri veya birkaçı bozulsa bile diğer robotlar sürü davranışını devam ettirirler. Toplanma davranışı tek bir robotun hareketlerinden daha çok sürünün hareketlerine bağlı kalır. Robotlar çoğunluğun bulunduğu yönde ilerler. Robotların aralarındaki mesafeyi korumaları için toplama metodu uygulanırken sabit hızda hareket etmektedirler. Robotlar bir araya toplansalar da platform üzerinde sürekli hareket halindedir.

\section{Sonuç}

Çalışmada sürü robotiğinden toplanma davranışı için bir toplanma davranışı metodu önerilmiş̧ir. Önerilen toplanma davranışında robotlar sınırlı algılama özelliklerini kullanarak bir araya gelmektedirler. Toplanma metodunda her robot sadece kendi kendine karar vermektedir. Sürüde bulunan robotların her biri algıladığı robotlardan en yakın olanı takip etmektedir. Bu takip aşamasında sürü robotları algıladığı robotların davranışına göre yönlenirler. Sürü robotları sadece özerk olarak sergilediği hareketinin yanı sıra sürü içinde ortak hareket sergilemektedir. Toplanma metodu ile robotlar her zaman çoğunluğun olduğu yöne doğru hareket eder. Bu davranış robotları birbirlerine yaklaştıır. Robotlar sınırlı algılama alanına sahip olduğundan, sadece algılanan robotların birbirine yaklaşması gruplaşmalar oluşturur. Toplanma metodu ile robotlar belirli mesafede yaklaştıklarında aynı yönde hareketlenirler. Bu durumda robotlar grup oluştursalar dahi aynı yönde hareket ederler ve diğer robot grupları ile birleşirler.

Çalışmada benzetim ortamında farklı arena boyutlarında ve farklı robot sayılarında sistematik deneyler uygulanmıştır. Sistematik deneyler yoluyla önerilen toplanma davranışının performansı incelenmiştir. Uygulanan bütün sistematik deneylerde robotlar bir araya gelmektedirler. Arena boyutunun büyümesi toplanma süresinin artırdığı gözlemlenmektedir. Robot sayısı artırılarak uygulanan sistematik deneylerde ise robot sayısı arttıkça toplanma davranışı performansının azaldığı gözlenmiştir. Arena boyunun değişmesi ve robot sayısının azalması toplanma süresini artırsa da sürü robotları esnek ve ölçeklenebilir bir davranış göstermişlerdir. Bu davranışı ile 
basit özelliklere sahip benzer robotlar kendi aralarında organizasyon oluşturabilmeleri için toplanmaktadırlar. Robotlardan biri veya birkaçı yürüttükleri toplama davranışı sırasında bozulsa dahi önerilen toplanma metodu diğer robotlar tarafından gerçekleştirilmektedir.

\section{Kaynakça}

Abuelhaija, A., Jebrein, A., \& Baldawi, T. (2020). Swarm robotics : Design and implementation. International Journal of Electrical and Computer Engineering, 10(2), 2173-2181. https://doi.org/10.11591/ijece.v10i2.pp2173-2181

Amé, J.-M., Halloy, J., Rivault, C., Detrain, C., \& Deneubourg, J. L. (2006). Collegial decision making based on social amplification leads to optimal group formation. Proceedings of the National Academy of Sciences of the United States of America, 103(15), 58355840. https://doi.org/10.1073/pnas.0507877103

Arvin, F., Samsudin, K., Ramli, A. R., \& Bekravi, M. (2011). Imitation of Honeybee Aggregation with Collective Behavior of Swarm Robots. International Journal of Computational Intelligence Systems, 4(4), $739-748$. https://doi.org/10.1080/18756891.2011.9727825

Arvin, F., Turgut, A. E., Bazyari, F., Arikan, K. B., Bellotto, N., \& Yue, S. (2014). Cue-based aggregation with a mobile robot swarm: a novel fuzzy-based method. Adaptive Behavior, 22(3), 189-206. https://doi.org/10.1177/1059712314528009

Bayındır, L. (2016). A review of swarm robotics tasks. Neurocomputing, 172, $292-321$. https://doi.org/10.1016/J.NEUCOM.2015.05.116

Brambilla, M., Ferrante, E., Birattari, M., \& Dorigo, M. (2013). Swarm robotics: a review from the swarm engineering perspective. Swarm Intelligence, 7(1), 1-41. https://doi.org/10.1007/s11721-012-0075-2

Camazine, S, Deneubourg, J. L., Franks, N. R., Sneyd, J., Theraulaz, G., \& Bonabeau, E. (2003). Self-Organization in Biological Systems: (Princeton Studies in Complexity). Princeton University Press.

Camazine, Scott., Deneubourg, J.-L., Franks, N. R., Sneyd, J., Theraulaz, G., \& Bonabeau, E. (2001). Self-organization in biological systems. Princeton University Press. Tarihinde adresinden erişildi https://press.princeton.edu/titles/7104.html

de Sá, A. O., Nedjah, N., \& Mourelle, L. de M. (2017). Distributed and resilient localization algorithm for Swarm Robotic Systems. Applied Soft Computing, 57, 738-750. https://doi.org/10.1016/J.ASOC.2016.07.049

Dudek, G., Jenkin, M. M., Milios, E., \& Wilkes, D. (1996). A taxonomy for multi-agent robotics. Autonomous Robots, 3(4), 375-397. https://doi.org/10.1007/BF00240651

Francesca, G., Brambilla, M., Trianni, V., Dorigo, M., \& Birattari, M. (2012). Analysing an Evolved Robotic Behaviour Using a Biological Model of Collegial Decision Making (ss. 381-390). Springer, Berlin, Heidelberg. https://doi.org/10.1007/978-3-64233093-3_38

Gauci, M., Chen, J., Dodd, T. J., \& Groß, R. (2014b). Evolving Aggregation Behaviors in Multi-Robot Systems with Binary Sensors (ss. 355-367). Springer, Berlin, Heidelberg. https://doi.org/10.1007/978-3-642-55146-8_25

Gauci, M., Chen, J., Li, W., Dodd, T. J., \& Groß, R. (2014a). Self-organized aggregation without computation. The International Journal of Robotics Research, 33(8), 1145-1161. https://doi.org/10.1177/0278364914525244

Gomes, J., Urbano, P., \& Christensen, A. L. (2013). Evolution of swarm robotics systems with novelty search. Swarm Intelligence, 7(23), 115-144. https://doi.org/10.1007/s11721-013-0081-z

Hamann, H., Worn, H., Crailsheim, K., \& Schmickl, T. (2008). Spatial macroscopic models of a bio-inspired robotic swarm algorithm. Içinde 2008 IEEE/RSJ International Conference on Intelligent Robots and Systems (ss. 1415-1420). IEEE. https://doi.org/10.1109/IROS.2008.4651038

Hu, D., Zhong, M., Zhang, X., \& Yao, Y. (2014). Self-organized aggregation based on cockroach behavior in swarm robotics. Içinde Proceedings - 2014 6th International Conference on Intelligent Human-Machine Systems and Cybernetics, IHMSC 2014 (C. 1, ss. 349-354). Institute of Electrical and Electronics Engineers Inc. https://doi.org/10.1109/IHMSC.2014.92

Kernbach, S., Häbe, D., Kernbach, O., Thenius, R., Radspieler, G., Kimura, T., \& Schmickl, T. (2013). Adaptive collective decisionmaking in limited robot swarms without communication. The International Journal of Robotics Research, 32(1), 35-55. https://doi.org/10.1177/0278364912468636

Khaldi, B., Harrou, F., Cherif, F., \& Sun, Y. (2018a). Self-organization in aggregating robot swarms: A DW-KNN topological approach. Biosystems, 165, 106-121. https://doi.org/10.1016/J.BIOSYSTEMS.2018.01.005

Khaldi, B., Harrou, F., Cherif, F., \& Sun, Y. (2019). Flexible and Efficient Topological Approaches for a Reliable Robots Swarm Aggregation. IEEE Access, 7, 96372-96383. https://doi.org/10.1109/ACCESS.2019.2930677

Martínez-Clark, R., Cruz-Hernández, C., Pliego-Jimenez, J., \& Arellano-Delgado, A. (2018). Control algorithms for the emergence of self-organized behaviours in swarms of differential-traction wheeled mobile robots. International Journal of Advanced Robotic Systems, 15(6), 172988141880643. https://doi.org/10.1177/1729881418806435

Nakano, R. C. S., Bandala, A., Faelden, G. E., Maningo, J. M., \& Dadios, E. P. (2014). A genetic algorithm approach to swarm centroid tracking in quadrotor unmanned aerial vehicles. Içinde 2014 International Conference on Humanoid, Nanotechnology, Information Technology, Communication and Control, Environment and Management (HNICEM) (ss. 1-6). IEEE. https://doi.org/10.1109/HNICEM.2014.7016217

Nedjah, N., \& Junior, L. S. (2019). Review of methodologies and tasks in swarm robotics towards standardization. Swarm and Evolutionary Computation, 50, 100565. https://doi.org/10.1016/j.swevo.2019.100565

Şahin, E., \& Bayındır, L. (2014). A Review of Studies in Swarm Robotics. Turkish Journal of Electrical Engineering and Computer Science, 15(2), 115-147. Tarihinde adresinden erişildi http://dergipark.gov.tr/tbtkelektrik/issue/12085/144468

Sathiya, V., \& Chinnadurai, M. (2019). Evolutionary Algorithms-Based Multi-Objective Optimal Mobile Robot Trajectory Planning. Robotica, 1-20. https://doi.org/10.1017/S026357471800156X 
Shao, J., Lin, H., \& Zhang, K. (2013). Swarm robots reinforcement learning convergence Accuracy-based learning classifier systems with Gradient descent (XCS-GD). Içinde Proceedings of 2013 3rd International Conference on Computer Science and Network Technology (ss. 1306-1309). IEEE. https://doi.org/10.1109/ICCSNT.2013.6967341

Shlyakhov, N. E., Vatamaniuk, I. V, \& Ronzhin, A. L. (2017). Survey of Methods and Algorithms of Robot Swarm Aggregation. Journal of Physics: Conference Series, 803, 012146. https://doi.org/10.1088/1742-6596/803/1/012146

Soysal, O., \& Sahin, E. (2005). Probabilistic aggregation strategies in swarm robotic systems. Içinde Proceedings 2005 IEEE Swarm Intelligence Symposium, 2005. SIS 2005. (ss. 325-332). IEEE. https://doi.org/10.1109/SIS.2005.1501639

Soysal, Onur, Bahçeci, E., \& Şahin Erol. (2007). Aggregation in Swarm Robotic Systems: Evolution and Probabilistic Control. Turkish Journal of Electrical Engineering and Computer Science, 15(2), 199-225. http://dergipark.gov.tr/download/article-file/125895

Trianni, V., Groß, R., Labella, T. H., Şahin, E., \& Dorigo, M. (2010). Evolving Aggregation Behaviors in a Swarm of Robots (ss. 865874). Springer, Berlin, Heidelberg. https://doi.org/10.1007/978-3-540-39432-7_93

Vanualailai, J., \& Sharma, B. N. (2010). A Lagrangian-based Swarming Behavior in the Absence of Obstacles. http://repository.usp.ac.fj/7380/

Yan, X., Liang, A., \& Guan, H. (2011). An algorithm for self-organized aggregation of swarm robotics using timer. Içinde 2011 IEEE Symposium on Swarm Intelligence (ss. 1-7). IEEE. https://doi.org/10.1109/SIS.2011.5952567

Yılmaz, Z., \& Bayındır, L. (2019). Simulation of Lidar-Based Robot Detection Task using ROS and Gazebo. European Journal of Science and Technology, 513-529. https://doi.org/10.31590/ejosat.642840 